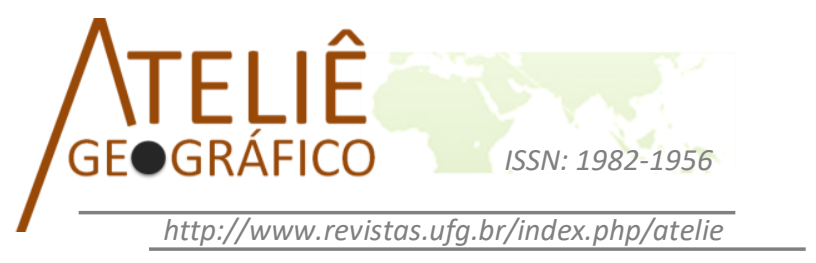

\title{
Políticas Públicas de Desenvolvimento Regional: uma análise a partir da atuação da primeira Superintendência de Desenvolvimento do Centro- Oeste (1967-1990)
}

\section{Public Policies of Regional Development: an analysis based on the acting area of the first Superintendence for the Mid-Western Development (1967-1990)}

\section{Politiques Publiques de Développement Régional: une analyse à partir de l'entrée en vigueur de la première Surintendance de Développement Du Centre-Ouest (1967-1990)}

\author{
Walter Guedes da Silva \\ Universidade Estadual do Mato Grosso do Sul \\ guedes@uems.br \\ Mateus Boldrine Abrita \\ Universidade Estadual de Mato Grosso do Sul \\ mateusabrita@hotmail.com
}

\begin{abstract}
Resumo
Considerada pelo governo militar como um vazio demográfico que deveria ser ocupado, a região Centro-Oeste brasileira vivenciou, durante os anos 70 e 80 do século 20 , um processo de modernização das atividades agrícolas e de consumo de produtos industriais. Uma integração que atendeu aos interesses do capital, que associado ao Estado brasileiro conduziu o Centro-Oeste à especialização na produção de commodities. Entre as estratégias utilizadas pelo governo, destacamos a criação da Superintendência de Desenvolvimento do Centro-Oeste (SUDECO), em 1967, que teve a tarefa de conduzir o Centro-Oeste a uma integração com as demais regiões do Brasil. Com o objetivo de analisar o papel da Primeira Sudeco (1967 a 1990) como órgão de planejamento e desenvolvimento do Centro-Oeste, esse trabalho foi conduzido por meio do levantamento da literatura regional que discute o papel da Superintendência no processo de desenvolvimento da região Centro-Oeste brasileira, de dados e indicadores estatísticos e dos documentos da própria Superintendência. A ação estatal na região foi fundamental para consolidar os interesses do capital agroindustrial com a integração da região Centro-Oeste à economia nacional.
\end{abstract}

Palavras-chave: Estado, planejamento, integração, commodities. 


\begin{abstract}
Considered by the military government as a demographic vacuum which should be occupied, the Brazilian mid-west region went through a process of modernization in its agricultural activities and demand for manufactured goods through the 70s and 80s of the 20th century. There was integration that fulfilled the interests of capital, and associated with the Brazilian Government, it led the Mid-West to specialize in the production of commodities. Among the strategies used by the government, we point out the creation of Superintendência de Desenvolvimento do Centro-Oeste (SUDECO), in 1967, which aimed to lead the Mid-West to integrate into the other regions in Brazil. With the objective of analyzing the role of the first Sudeco (from 1967 to 1990) as a planning and development institution in the Mid-West, this work was carried out through analyzing regional literature that discuss the role of the Institution in the development process of the Brazilian mid-west region, and also the Institution's data, statistical indicators and documents. The governmental action in the region was essential to consolidate the interests of agricultural and industrial investments with the integration of the Mid-West region into the national economy.
\end{abstract}

Keywords: State, planning, integration, commodities.

\begin{abstract}
Résumé
Considerée, à l'époque du régime militaire, comme un vide démographique destiné à être peuplé, la région du centre-ouest brésilien a connu, durant les années 1970 et 1980, un processus de mordernisation de ses activités agricoles et de consommation de produits industriels. Lié aux intérêts du capital, cet effort d'intégration, en association avec l'État brésilien, a conduit la région du Centre-Ouest vers l'expertise dans la production de commodities. Parmi les stratégies mises en place par le gouvernement se situe, en particulier, la création de la Surintendance de Développement du Centre-Ouest (Sudeco) en 1967, dont le but était de promouvoir une intégration avec les autres régions du Brésil. Ayant pour but d'analyser le rôle de la première Sudeco (1967-1990) en tant qu'organe de plannification et de développement du Centre-Ouest, cette recherche s'est basée sur la révision de la littérature régionale disponible, notamment le rôle de la Surintendance dans le processus de développement de la région Centre-Ouest brésilienne. Sont également présentés des données, des indicateurs statistiques et des documents élaborés par la Surintendance. L'action de l'état dans la région a joué un rôle fondamental dans la consolidation des intérêts du capital agro-industriel, à la suite de l'intégration de la région dans l'économie nationale.
\end{abstract}

Mots-clés: État, plannification, intégration, commodities.

\title{
Introdução
}

A precariedade ainda presente nos meios de transporte e energia na região Centro-Oeste (CO), que perdurou do início do século 20 até o final dos anos 60, inviabilizava uma efetiva integração dessa região à economia nacional. O Estado atuou com políticas de integração do $\mathrm{CO}$ à economia nacional e criou a Superintendência de Desenvolvimento do Centro-Oeste (Sudeco), em 1967, órgão vinculado ao Ministério do Interior que teve como objetivo integrar o $\mathrm{CO}$ à dinâmica produtiva nacional.

Os investimentos dessa Primeira Sudeco foram direcionados para a infraestrutura de transporte, energia, armazenamento, pesquisa e assistência técnica, mas foram os setores de transporte e energia quem mais receberam recursos, pois as dificuldades de circulação de mercadorias ainda eram um empecilho ao processo de reprodução do capital. 
A ação da Primeira Sudeco no CO contribuiu para que o campo se modernizasse, tornando-se mais um nicho de mercado para a acumulação industrial via agroindustrialização, não desempenhando somente a função de celeiro produtivo nacional, mas de um cliente da indústria. Uma modernização classificada por George Martine (1990) como modernização conservadora, em que as atividades agrícolas incorporaram a estrutura da dinâmica industrial, comercial e financeira do novo padrão produtivo que se estabeleceu, conservando, porém, a desigualdade social presente no campo.

Esse novo padrão produtivo (re)configurou a organização espacial do campo no CO para atender aos interesses do capital industrial, que alterou as relações de trabalho, a produção, as técnicas de trabalho, a estrutura fundiária, a prestação dos serviços e as vias de comunicação, transporte e circulação, revelando, à luz das políticas de desenvolvimento nacional, um modelo de organização da agricultura subordinado à indústria.

Deste modo, este artigo objetiva analisar a atuação da Primeira Sudeco como órgão de planejamento e desenvolvimento da região CO no período de 1967 a 1990. Para isso, esse trabalho está organizado em quatro partes: introdução, onde são apresentados elementos necessários à compreensão do tema; a atuação da Sudeco no desenvolvimento do Centro-Oeste com análise de indicadores como imigração, crescimento agropecuário, industrial e seu papel como promotor do desenvolvimento; posteriormente serão analisados os aspectos socioeconômicos deste período e, por fim, as considerações finais.

\section{A Sudeco e as políticas de desenvolvimento do Centro-Oeste (1967-1990)}

Criada pela Lei N 5.365 de 01 de dezembro de 1967, na gestão Costa e Silva (1967-1969), a Primeira Sudeco priorizou recursos que viabilizassem a circulação da produção agrícola e o consumo de produtos industriais. Sua criação contribuiu para que o $\mathrm{CO}$ recebesse o fluxo de migrantes, principalmente aqueles oriundos do Nordeste, e para a expansão da fronteira agrícola do país. Esses movimentos populacionais podem ser melhores observados na tabela 1 .

Tabela 1: Taxa de imigração líquida por estados do Centro-Oeste e Distrito Federal

\begin{tabular}{|c|c|c|c|c|}
\hline & Goiás & Mato Grosso & Mato Grosso do Sul & Distrito Federal \\
\hline 1950 & 23,16 & 14,95 & - & - \\
\hline 1960 & 26,95 & 24,51 & - & 93,55 \\
\hline 1970 & 25,21 & 32,09 & - & 76,76 \\
\hline 1980 & 23,12 & 35,41 & 43,15 & 67,2 \\
\hline
\end{tabular}

Fonte: IBGE, 2015. 
No período de 1950 a 1980, houve significativo aumento da população do Centro-Oeste em função do aumento na taxa de imigração líquida. $\mathrm{O}$ aumento na imigração para o Distrito Federal justifica-se pela própria construção de Brasília iniciada em 1956 e inaugurada em 1960. Na figura 1 é possível observar que o crescimento da população nas capitais do Centro-Oeste ocorreu de forma diferenciada, mais intensa em algumas cidades como Brasília e Goiânia, que apresentaram um crescimento de população total muito superior às capitais Campo Grande e Cuiabá.

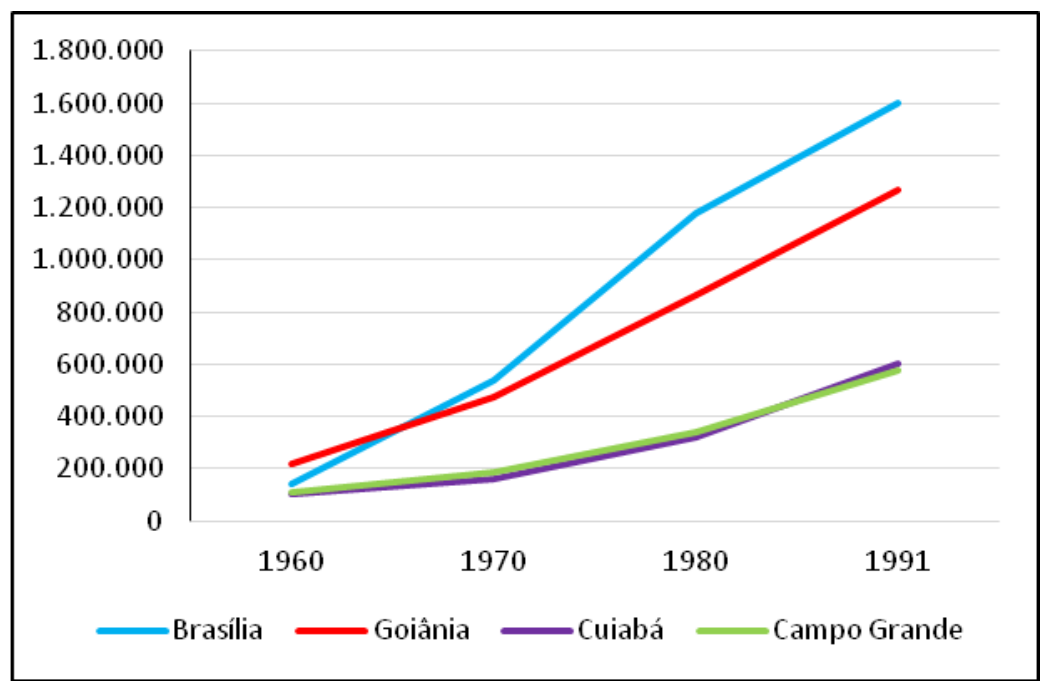

Figura 1: População total das capitais dos estados do Centro-Oeste e Distrito Federal Fonte: IBGE, 2015.

Em 1967, o Ministro do Interior deixou claros os propósitos da Sudeco para a expansão da fronteira agrícola do país, cabendo a esse órgão o "relevante papel na integração do centro-oeste, como instrumento positivo para o deslocamento das fronteiras econômicas do país que devem coincidir com as linhas demarcatórias da soberania política nacional" (MINISTÉRIO DO INTERIOR, 1968, p. 24).

Discutindo especificamente a importância do $\mathrm{CO}$ em absorver "os excessos populacionais para integrá-los em sua economia, como fator positivo do trabalho" (MINISTÉRIO DO INTERIOR, 1970, p. 02), o primeiro superintendente da Sudeco, Sr. Sebastião Dante de Camargo Júnior, declarou:

Isso só não virá a amparar essa população, tornando-a mais produtiva, como contribuirá para a expansão do nosso mercado interno, medida necessária a consolidação da estrutura industrial que se desenvolve na região Leste-Sul do país. Essa concentração demográfica que se vai processar, no Planalto Central, deverá caminhar, progressivamente, no sentido da Amazônia, exercendo, inicialmente, 
atividade agrícola e, posteriormente, deixará a sua retaguarda, uma estrutura econômica e social definida, capaz de funcionar como suporte para o avanço dessa nova fronteira humana, que atingirá o vale Amazônico (MINISTÉRIO DO INTERIOR, 1970, pp. 02-03).

O então Presidente do Brasil, Marechal Costa e Silva, evidenciou a ideia de integração do território como possibilidade de deslocamento da população pobre do Nordeste para o Centro-Oeste, destacando que o papel dessa região não se resumia apenas como produtora de alimentos e consumidora de produtos industriais, mas como receptora de migrantes pobres do Nordeste que se converteriam em trabalhadores do campo. "Isso deve ser, realmente, um dos objetivos primaciais do Ministério do Interior, estabelecendo esta política de deslocamento de populações para zonas mais favoráveis de vida" (MINISTÉRIO DO INTERIOR, 1968, pp. 40-41).

O CO era um espaço de transição entre o capitalismo já consolidado do Sudeste e a emergente fronteira de recursos da Amazônia. O discurso oficial do Governo de "soberania nacional" e "desenvolvimento harmônico", serviram para escamotear os reais interesses de o governo militar que estava aos interesses do capital industrial e de grupos vinculados as multinacionais. Segundo Cavalcanti; Barreira (2011, p. 181), esses grupos tinham propósitos de aumentar a dependência das atividades agrícolas para com os produtos industriais, como fertilizantes e adubos, reivindicando "ações governamentais que promovessem a expansão da fronteira agrícola, nos moldes da moderna agropecuária, justificando tais medidas como a única opção para acabar com a fome no mundo."

Com o propósito de ampliar o mercado nacional sustentado na expansão da fronteira agrícola do país para os chamados vazios demográficos, o governo federal criou o I Plano Nacional de Desenvolvimento (I PND), com vigência entre o período de 1971-1974, que, entre outros objetivos, visava interligar o CO aos centros consumidores e fornecedores de produtos industrializados.

Esse esforço pode ser notado pela expressiva elevação do estoque líquido de capital privado em máquinas e equipamentos na agropecuária. A figura 2 demonstra um crescimento maior nos estados de Mato Grosso do Sul e Goiás, embora Mato Grosso apresente um crescimento relevante a partir de 1975.

Ao comparar os valores do Centro-Oeste com outras regiões do país (figura 3), é possível observar uma consistente elevação marginal, assim como a desigualdade entre as regiões brasileiras, principalmente em relação às regiões Sul e Sudeste. Todavia, fica demonstrado que o Centro-Oeste minimizou a disparidade em relação a máquinas e equipamentos agrícolas no período analisado. 


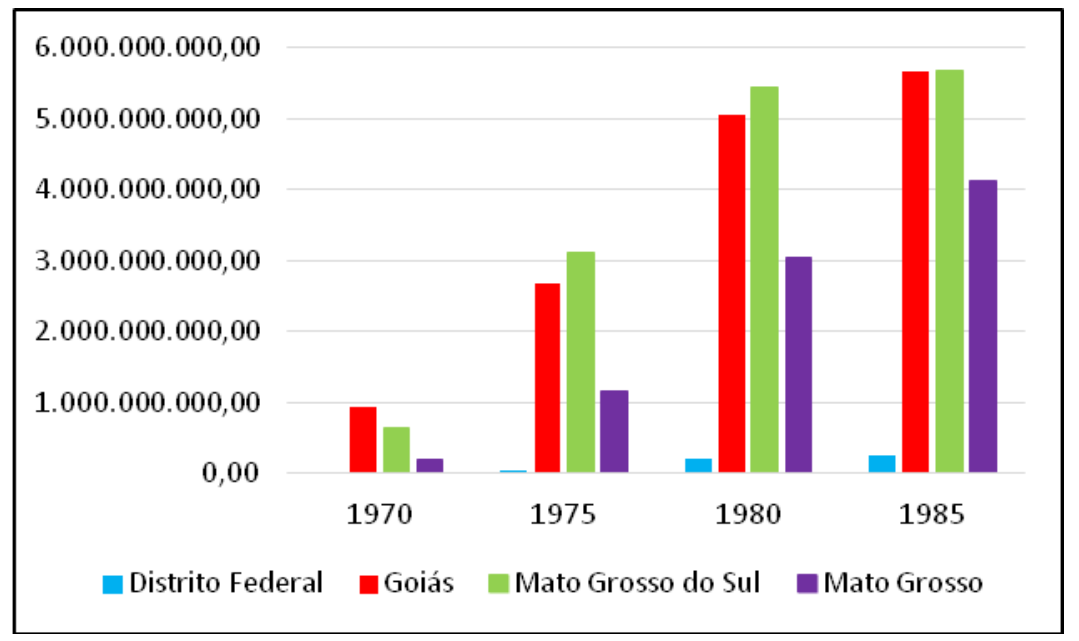

Figura 2: Estoque líquido de capital privado de máquinas e equipamentos na agropecuária nos estados do Centro Oeste e Distrito Federal ( $\mathrm{R} \$$ de 1999) Fonte: IPEA, 2015.

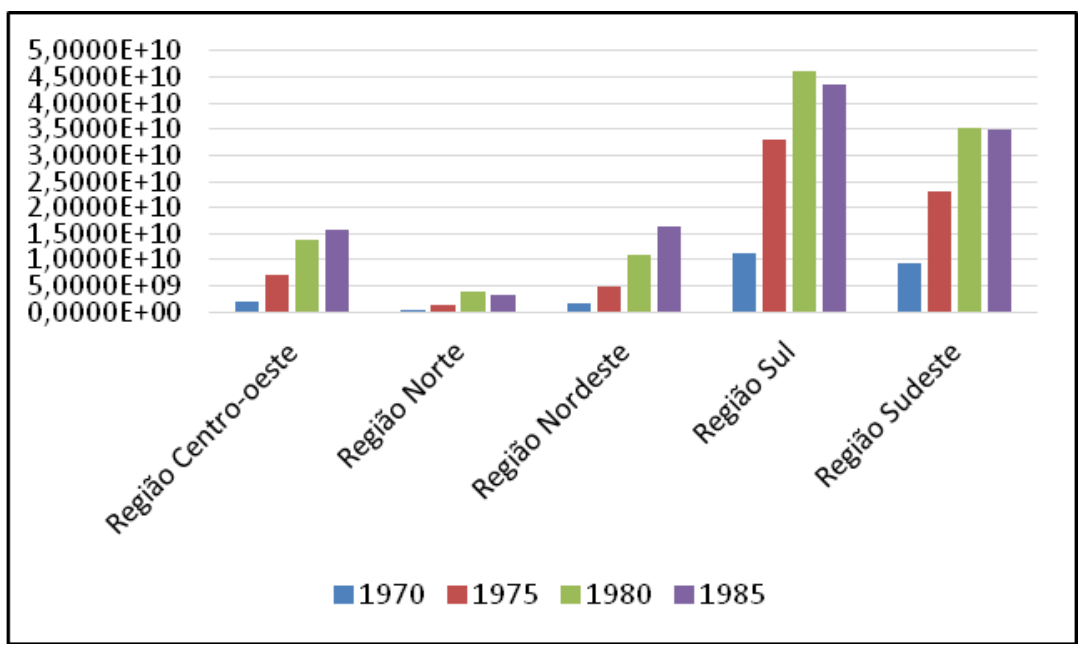

Figura 3: Estoque líquido de capital privado de máquinas e equipamentos nas regiões brasileiras ( $\mathrm{R} \$$ de 1999). Fonte: IPEA, 2015.

Avançando para a análise de máquinas e equipamentos privados na área industrial, a figura 4 demonstra que houve avanço em todo o Centro-Oeste, mas com relevante concentração no estado de Goiás. 


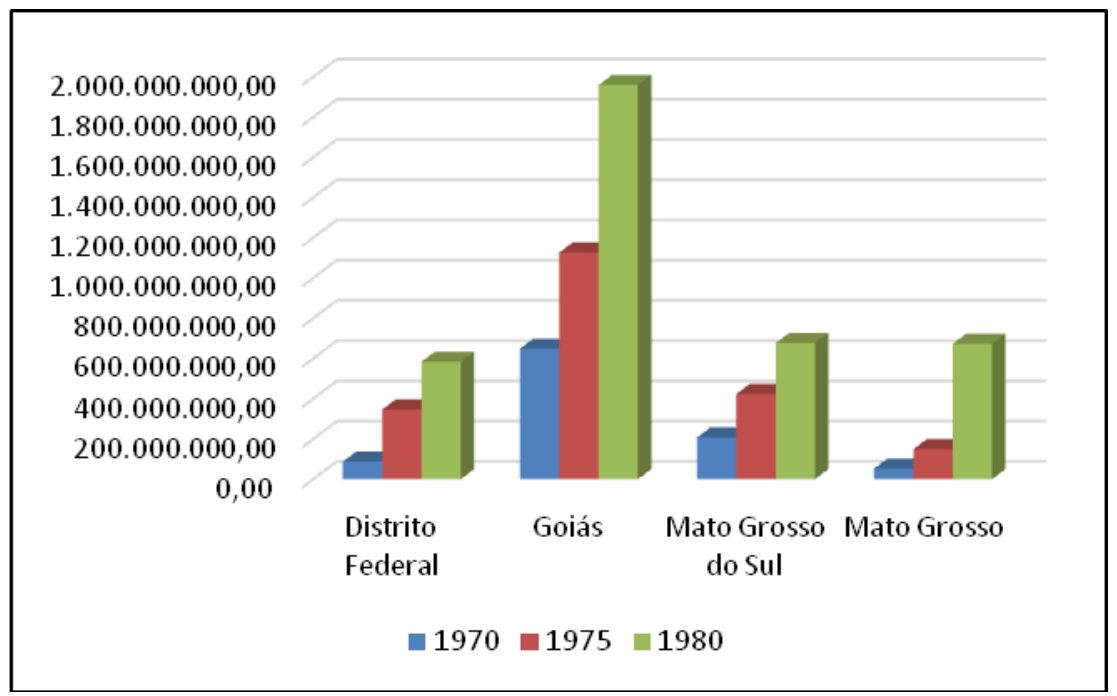

Figura 4: Estoque líquido de capital privado de máquinas e equipamentos na indústria nos estados do Centro-Oeste e Distrito Federal ( $\mathrm{R} \$$ de 1999)

Fonte: IPEA, 2015.

Os incentivos recebidos para a modernização e integração do campo aos mercados consumidores, incrementaram a produção destinada à exportação e consolidaram a integração do mercado interno, levando o $\mathrm{CO}$ a se tornar um grande cliente das multinacionais detentoras do controle dos equipamentos, maquinários e insumos. A meta era exportar e agroindustrializar os produtos agrícolas.

Para isso é necessário, entre outras iniciativas, que se aumente a produção de alimentos básicos para o consumo da população, gerandose, ao mesmo tempo, excedentes exportáveis; que se retomem gradualmente os níveis de emprego e de demanda interna, através do aproveitamento da capacidade produtiva industrial (GOVERNO DO ESTADO DE MATO GROSSO DO SUL, 1985, p. 11).

Para se integrar a lógica de produção e acumulação capitalista, a Sudeco previu duas frentes de ação: uma estava voltada ao mercado externo que incentivou a produção de grãos (principalmente a soja), da pecuária bovina e da mineração importante mecanismo de geração de divisas e manutenção da balança comercial; e a outra estava direcionada ao mercado interno como região consumidora de produtos industrializados. Tais propósitos foram alcançados com relativo sucesso quando se analisa o rebanho bovino efetivo e produção de soja em grãos dos estados do CentroOeste e DF. 


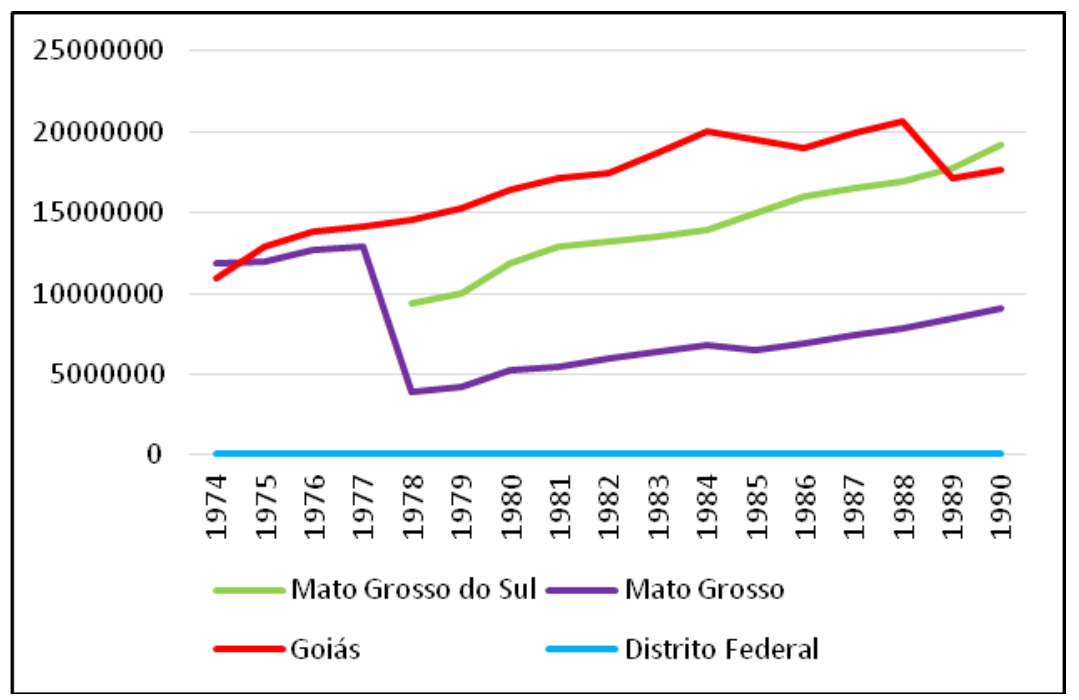

Figura 5: Rebanho bovino efetivo (cabeça) dos estados do Centro-Oeste e Distrito Federal. Fonte: IBGE, 2015.

A figura 5 revela o crescimento acelerado do rebanho efetivo de bovinos, muito relacionado a abertura de pastagens e da pecuária de corte. É importante destacar que a queda no ano de 1978 no estado de Mato Grosso justifica-se pela criação do estado de Mato Grosso do Sul. A figura 6 demonstra a produção de soja em várias das regiões do Brasil, com destaque para as regiões Sul e Centro-Oeste.

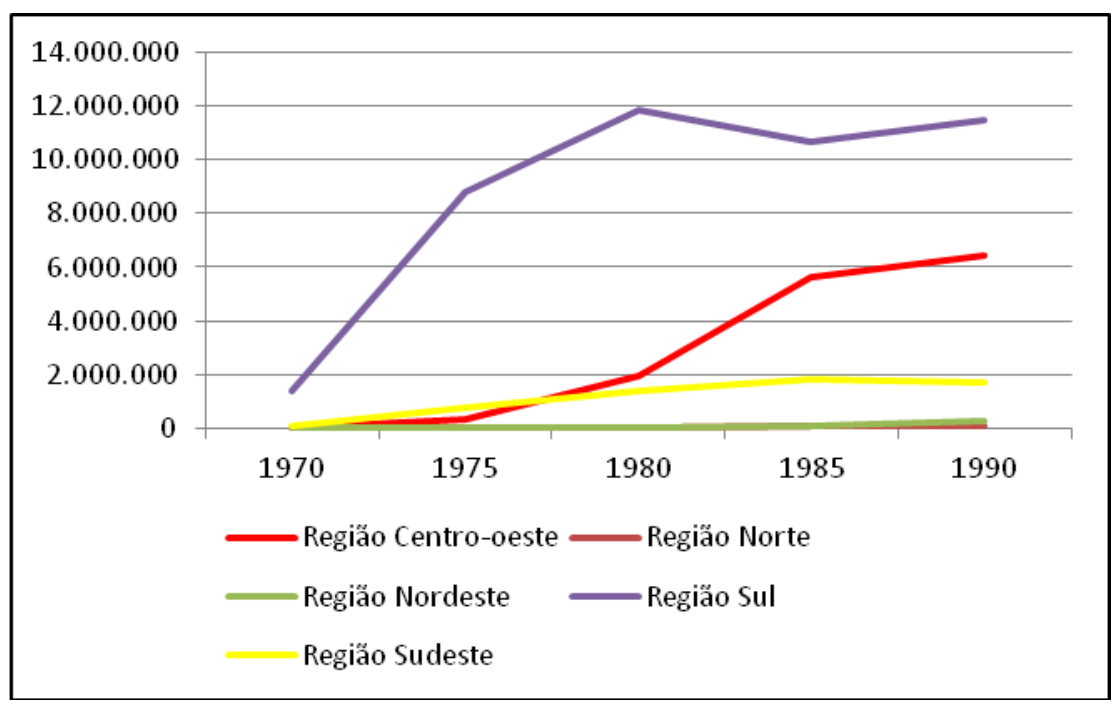

Figura 6: Produção de soja em grãos (ton.) por regiões do Brasil. Fonte: IBGE, 2015. 
Em relação à atividade industrial, a tabela 2 demonstra o número total de estabelecimentos nos estados do CO nos quinquênios de 1970 a 1995, evidenciando, também, que o crescimento da atividade industrial se deu de forma desigual no território.

Tabela 2: Número total de estabelecimentos ou unidades industriais nos estados do Centro-Oeste e Distrito Federal

\begin{tabular}{|lrrrrr|}
\hline & $\mathbf{1 9 7 0}$ & $\mathbf{1 9 7 5}$ & $\mathbf{1 9 8 0}$ & $\mathbf{1 9 8 5}$ & $\mathbf{1 9 9 5}$ \\
\hline Distrito Federal & 403 & 625 & 1199 & 1066 & 2810 \\
Goiás & 4022 & 5338 & 6313 & 5939 & 10701 \\
Mato Grosso do Sul & 1592 & 1994 & 2671 & 2309 & 3528 \\
Mato Grosso & 878 & 1298 & 2357 & 1924 & 5945 \\
\hline
\end{tabular}

Fonte: IBGE, 2015.

O estado de Goiás concentra boa parte desses estabelecimentos ou unidades industriais, apresentando um crescimento substancial no período, de aproximadamente $166 \%$. Todavia, o crescimento ocorre em todos os estados como é o caso do Distrito Federal que mais que dobrou estas unidades no período em análise. Portanto, a região CO ganha destaque com um crescimento significativo na agropecuária e um certo avanço na indústria, principalmente em Goiás.

Com discurso de planejamento o I PND elaborou, a partir da realização de diagnósticos e prognósticos para ações a médio e longo prazos, o I Plano de Desenvolvimento Econômico e Social do Centro-Oeste (I Pladesco), com vigência para o período de 1973-1974, propondo estudos que viabilizassem a ampliação de atividades econômicas como soja e minérios.

Para atingir essa meta, o I Pladesco definiu 13 áreas-programas como Polos de Desenvolvimento regional, que conduziu os Programas do Pladesco por meio de diagnósticos e prognósticos que possibilitassem o desenvolvimento regional via planejamento estatal. Esse conceito é amparado pela teoria do economista francês François Perroux (1967) e de geógrafos como Manuel Correia de Andrade (1974), nesse conceito, o território é caracterizado a partir da influência econômica dos polos de planejamento.

De acordo com Lima; Simões (2015) e Perroux (1967) para melhor entender o processo de crescimento econômico que ocorre pelos "polos de crescimento", é necessário observar a existência de três questões principais deste processo: a indústria chave, o regime não concorrencial do complexo produtivo e a concentração territorial do complexo.

As indústrias-chaves apresentam posições privilegiadas de aplicação das forças ou dinamismo de crescimento. O regime não concorrencial do complexo produtivo é um arranjo de forças instáveis oligopolistas, que objetivam elevar a 
produtividade da indústria e proporcionar uma acumulação de capital superior ao nível que ocorreria com maior concorrência. Por fim, a concentração territorial do complexo forma um polo industrial geograficamente concentrado, com avanço de atividades econômicas resultante da proximidade e da concentração urbana, assim, o próprio polo transforma seu meio geográfico imediato.

Desse modo, Lima; Simões (2015) argumentam que a economia, no âmbito nacional, se revela com duas facetas: a primeira formada por conjuntos relativamente ativos e composta por indústrias "motrizes" que são polos de indústria e de atividades geograficamente concentradas, formando um complexo industrial; e a segunda é formada pelo conjunto de indústrias "movidas", apresentam características mais passivas e são mais dependentes dos polos concentrados. As implicações inatas deste processo de desenvolvimento podem resultar em conflitos de espaços econômicos, desequilíbrios sociais e econômicos.

De acordo com Souza (1993) um complexo industrial é composto por um arranjo de atividades relacionadas por relações de insumo-produto. $\mathrm{O}$ polo de crescimento será formado quando for liderado por uma ou mais indústrias motrizes; e por sua vez se transformará em um polo de desenvolvimento quando resultar em transformações estruturais e expandir o produto e o emprego em seu meio.

Outro ponto importante está na relação entre a teoria schumpeteriana do desenvolvimento e a teoria dos polos.
A teoria dos polos tem pontos de contato com a abordagem schumpeteriana do desenvolvimento. Em primeiro lugar, ela se baseia no dinamismo da indústria motriz, atividade inovadora e de grande dimensão, que exerce importantes efeitos de encadeamento no interior do polo. Em Schumpeter, a atividade inovadora rompe o fluxo circular estacionário e promove o crescimento de seu meio e leva outras empresas a inovarem em um processo de imitação. As empresas que não adaptam desaparecem (destruição criadora), liberando fatores produtivos a serem empregados pelas empresas inovadoras (SOUZA, 2005, p. 100).

Na abordagem clássica de Perroux, a relação com a inovação fica implícita e não tão evidenciada quanto em Schumpeter. De acordo com Souza (2005), o que acaba ocorrendo na realidade das economias é o direcionamento dos investimentos públicos para áreas de infraestrutura e atividades diretamente produtivas, criando ou fortalecendo polos existentes. Tal modelo de crescimento tem ocorrido de modo desigual no espaço, resultando em migrações interregionais e empobrecimento de regiões mais periféricas.

A criação de áreas-programas contribuiu para fomentar as atividades econômicas que apresentavam maior potencial de competitividade internacional, sendo também uma estratégia para concentrar os escassos recursos da Superintendência e criar as economias de aglomeração.

O I Pladesco priorizou áreas-programas que receberiam os investimentos públicos e privados numa clara estratégia de formar polos de desenvolvimento 
regional. No I Pladesco a ideia de planejamento, como estratégia para o desenvolvimento regional, assumiu grande importância entre os técnicos da Sudeco.

Os estudos realizados pelo I Pladesco nortearam as ações do II PND (19751979), que teve como meta aumentar a produção de gêneros alimentícios para a exportação. Essa foi uma das estratégias do governo para equilibrar a balança comercial em época de elevação do valor do combustível devido à crise do petróleo de 1973, além de criar condições para a substituição de importação em setores estratégicos como fertilizantes e equipamentos agrícolas.

O II PND reafirmou o papel do $\mathrm{CO}$ como região produtora de produtos agropecuários para exportação e como região receptora de correntes migratórias. Isso significa, na visão do Ministério do Interior (1974, p. 33), "efetivar a vocação do Brasil como supridor mundial de alimentos, matérias-primas agrícolas e produtos agrícolas industrializados."

A escolha das áreas-programas foi pensada para atender a necessidade de ocupação das áreas que apresentavam maior possibilidade de desenvolvimento de atividades econômicas comercialmente competitivas, como mineração, pecuária e soja. Isso fez com que essas áreas-programas tivessem um recorte descontínuo que "deveriam estar vinculadas à orientação das atividades de exportação, ligadas ao chamado corredores de exportação e aos setores dinâmicos do mercado internacional" (ABREU, 2001, p. 103).

Os Programas de desenvolvimento regional pensados no contexto do II PND foram: Programa Especial de Desenvolvimento da Região do Pantanal MatoGrossense (Prodepan), Programa de Polos Agropecuários e Agrominerais da Amazônia (Polamazônia), Programa de Desenvolvimento dos Cerrados (Polocentro), Programa Especial de Desenvolvimento da Região Geoeconômica de Brasília (PERGEB) e Programa Especial de Desenvolvimento da Região da Grande Dourados (Prodegran).

Os Programas criados no contexto do II PND e administrados pela Sudeco foram orientados para as lavouras de caráter comercial, pecuária de corte, indústria de mineração e madeireira, e agroindustrialização das atividades agrícolas, contribuindo para que essas atividades assumissem uma lógica de produção empresarial, ampliando o saldo da balança comercial brasileira.

Os dados da Fundação João Pinheiro (1984) demonstram que 2/3 dos recursos do Polocentro, destinados à pesquisa, foram orientados para a soja, mais de $75 \%$ do crédito liberado foram para as propriedades rurais, acima de 500 ha das áreasprogramas, e menos de $0,4 \%$ foi destinado às propriedades com menos de 100 ha, evidenciando o direcionamento de recursos para setores e regiões específicos.

O objetivo é levar a capacidade empresarial, que já se mostrou apta a desenvolver a indústria e outros setores urbanos, à atividade agropecuária nacional. Através de ampla disseminação da empresa rural - pequena, média e grande -, principalmente pelo apoio financeiro e fiscal do 
Governo, melhor se equacionarão problemas como o de induzir ao uso de projetos, de levar em conta os cálculos de rentabilidade e estímulos de preços, de empregar mais moderna tecnologia, considerando a relação entre preços de insumos e de produtos (MINISTÉRIO DO PLANEJAMENTO, 1974, p. 43).

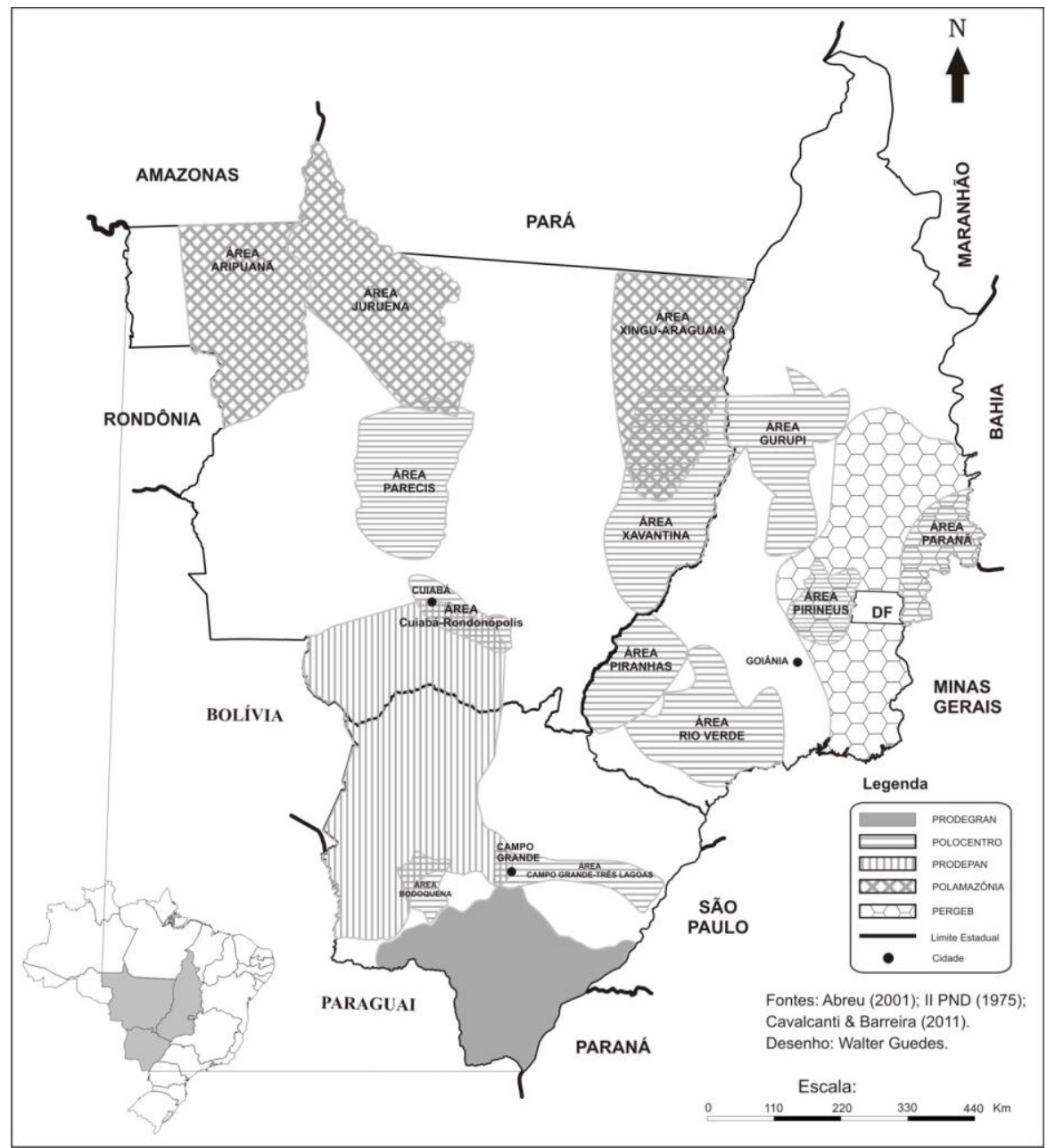

Figura 7: Área aproximada das áreas-programas do II PND no Centro-Oeste

Este avanço pode ser evidenciado pela elevação da utilização de terras de pastagens artificiais e pela área colhida de produção vegetal na região $\mathrm{CO}$, que pode ser observado na figura 8 e na tabela 3 . 


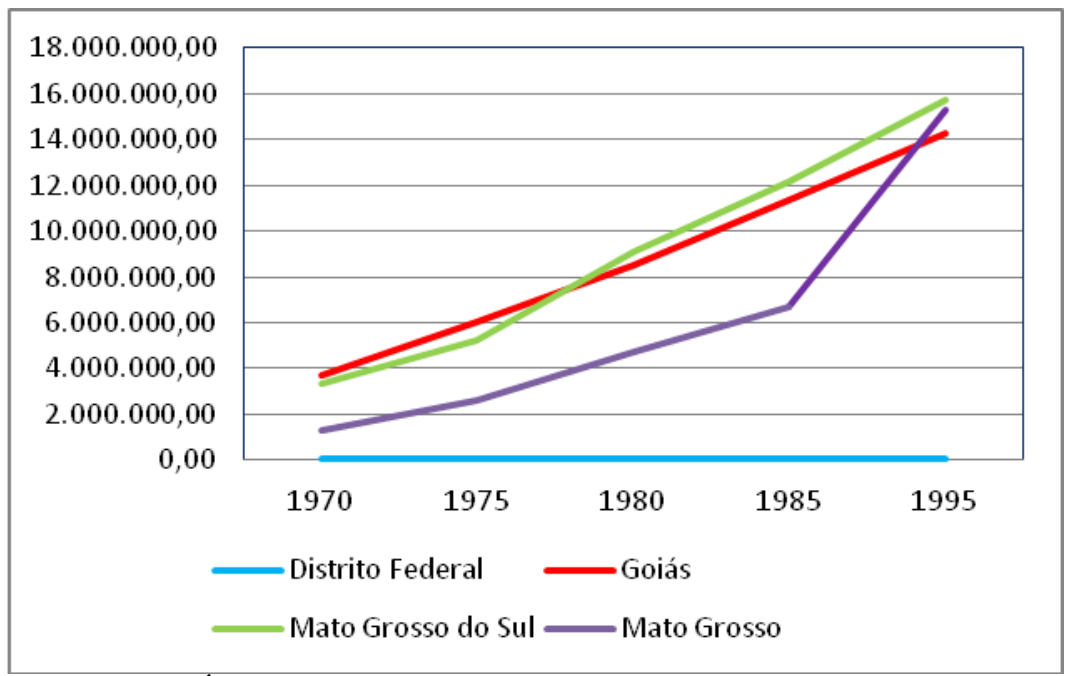

Figura 8: Área (ha) de pastagens plantadas (artificiais) dos estados do Centro-Oeste e Distrito Federal. Fonte: IBGE, 2015.

A utilização das terras apresentou uma elevação expressiva no período de 1970 até 1995 na região CO, a exceção ficou por conta do Distrito Federal, o que coaduna perfeitamente com os interesses do Estado e do Capital agroindustrial para o cultivo de grãos e pecuária nos estados do CO.

Tabela 3: Área (ha) colhida de soja e milho nos estados do Centro-Oeste e Distrito Federal

\begin{tabular}{|l|r|r|r|r|}
\hline & $\mathbf{1 9 7 0}$ & $\mathbf{1 9 7 5}$ & $\mathbf{1 9 8 0}$ & $\mathbf{1 9 8 5}$ \\
\hline Milho & 768.379 & 1.315 .983 & 1.565 .805 & 2.010 .987 \\
\hline Soja & 24.568 & 250.160 & 1.509 .861 & 4.646 .369 \\
\hline
\end{tabular}

Fonte: IBGE, 2015.

A tabela 3 revela um elevado crescimento da área colhida de soja e de milho na região Centro-Oeste. Na década de 1970, a área colhida de milho e soja era de 768.379 ha e 24.568 ha respectivamente, saltando para 2.010.987 ha e 4.646.369 ha em 1985, um crescimento total de área colhida de soja e milho de quase $740 \%$.

A ideologia de um desenvolvimento pautado em atividades econômicas como soja, pecuária e mineração, que atendiam mais aos interesses do capital monopolístico do que da sociedade, não coadunava com os anseios da sociedade que, durante o mandato do General João Figueiredo (1979-1985), último presidente do regime militar, manifestava seu anseio por um regime democrático e descentralizado. 
Para superar as adversidades políticas e econômicas do país, foi criado o III PND (1980-1985) que, na busca de dar respostas à sociedade, adotou termos e conceitos que eram bem vistos por muitos grupos sociais, como: democracia, direitos humanos, reforma agrária, descentralização e desenvolvimento sustentável. Apesar do III PND inserir, em seu discurso, temas tão almejados pela sociedade, a essência ainda era um desenvolvimento via especialização produtiva, mais especificamente, em produtos de exportação. Mudou-se a forma, mas o conteúdo continuou o mesmo.

Quando o III PND foi criado, o contexto econômico do país não era dos mais favoráveis, pois a falta de recursos inviabilizou muitos projetos. O modelo de planejamento centralizador adotado pelos I e II PNDs, que concentrou recursos em áreas e setores específicos, mostrou-se pouco eficiente. A Sudeco passava por um processo de esvaziamento institucional e por questionamentos quanto a sua eficiência e necessidade de existência.

Vale registrar que a atuação da Sudeco no CO ocorreu num contexto de divisão regional do trabalho que beneficiou o estado de São Paulo como centro hegemônico do capital nacional. Desde a crise de 1929, as mudanças que se processam no território brasileiro não provocaram apenas o deslocamento do eixo de acumulação do setor agroexportador para o industrial, pois a limitação às importações, ocorrida pela desarticulação do comércio externo, obrigou ao aumento da complementaridade inter-regional, onde as regiões menos industrializadas (periferia) comprariam produtos manufaturados de São Paulo (centro), e este importaria matéria-prima daquele. Passava-se, portanto, a integrar o mercado nacional sob o predomínio de São Paulo. À periferia nada mais restava do que se ajustar a uma função complementar da economia de São Paulo (CANO 2007, p. 61).

A manutenção da demanda interna nacional, juntamente com o corte das importações, revelou, para a indústria nacional, a incumbência de abastecer o mercado interno. Mas só o potencial industrial de São Paulo com capacidade de produção ociosa, não lhe garantia, por si só, o posto de centro dinâmico da economia capitalista, fazia-se necessário uma integração nacional.

O novo padrão de acumulação seria dominado pelo capital industrial e
este, majoritariamente, está sediado em São Paulo; era ali onde se
concentravam seus maiores interesses, maior mercado, maior capacidade
de articulação inter-setorial, maiores ganhos de escala e de economias
externas e o mais bem constituído mercado de trabalho (CANO, 2007,
p.185-6).

Para sobreviver a esta acirrada competição inter-regional, o Centro-Oeste além de manter seu vínculo com o mercado internacional (agroexportação), assume o papel de economia complementar de São Paulo, afinal, "o maior nível de atividade industrial reclama maior uso de matérias-primas, combustível e bens de capital" (CANO, 2007, p. 181). 
Era a economia de São Paulo que passava a promover a integração do mercado nacional, de forma crescente, tornando-se o centro da decisão maior da acumulação de capital do país. Vista a questão de outra forma, a periferia nacional não mais poderia "percorrer iguais caminhos" percorridos por São Paulo; vale dizer, não teria mais sentido pensar como ingenuamente alguns ainda hoje pensam - em uma industrialização "autônoma" na periferia nacional (CANO, 2007, p.50).

As regiões próximas de São Paulo como: Goiás, Mato Grosso, Minas Gerais e Paraná, principalmente aquelas com menos densidade demográfica, estavam mais predispostas a receber impactos positivos de integração, estas regiões seriam de avanço da fronteira agrícola. Não foi a condição de "vazio" que possibilitou a maior proximidade econômica com São Paulo, mas porque tinham melhores condições de assimilar o impacto do crescimento emanado a partir de São Paulo, com uma integração via agropecuária.

A Sudeco entra em crise a partir de meados dos anos 80. Alguns aspectos contribuíram para isto como: falta de autonomia financeira da Superintendência, escassez de recursos, aumento da inflação, crise do modelo de desenvolvimento e planejamento, incapacidade da Superintendência em responder aos anseios do capital industrial, fortalecimento das discussões em torno dos direitos humanos e do meio ambiente, sem contar o próprio processo de redemocratização do país que não comungava com o modelo de desenvolvimento adotado pela Superintendência.

Conhecida no âmbito econômico como a década perdida, os anos de 1980 foram caracterizados por uma dura crise na economia brasileira. Rego; Marques; et. al. (2003) demostram que o período apresenta uma série de problemas econômicos como instabilidades internacionais, crise cambial, déficits na balança de pagamentos e das contas públicas, baixo dinamismo do crescimento do Produto Interno Bruto (PIB), altas taxas de juros e inflação elevada.

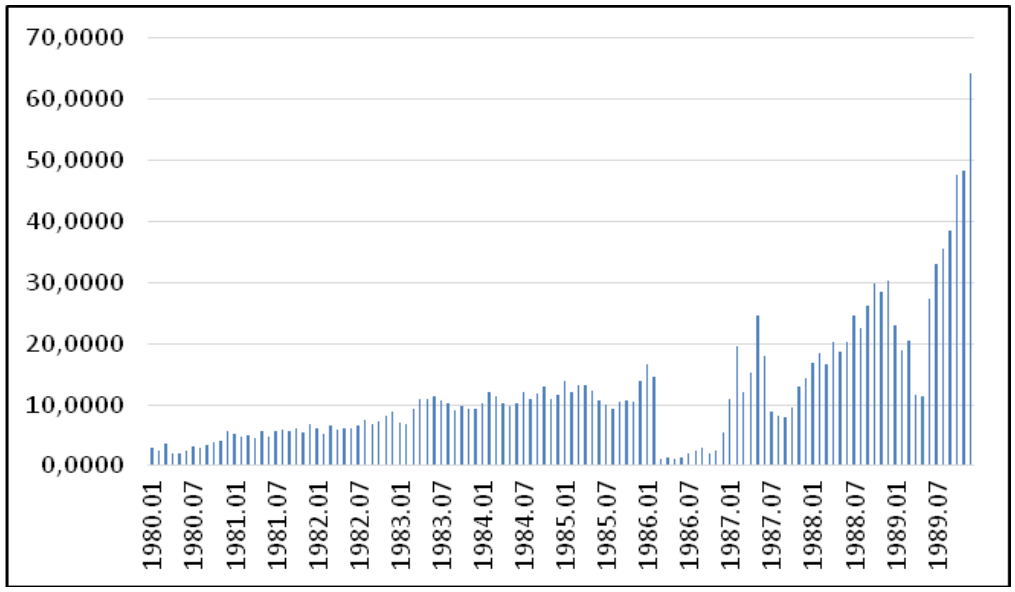

Figura 9: Taxa de juros do Brasil - Over/Selic (\% a.m.). Fonte: IPEA, 2015. 
A taxa de juros Selic é a taxa básica de juros da economia brasileira e serve de referência para todas as demais taxas de juros. A figura 9 apresenta a evolução desta taxa nos anos 1980 e os valores gravitam em patamares elevados já no início da década, atingindo o impressionante patamar de 64,2\% em dezembro de 1989, evidenciando o grau de desequilíbrio que a economia brasileira enfrentava. Outra importante variável para mensurar a saúde financeira de um país é a taxa de inflação, a tabela 4 mostra a evolução do Índice de Preços ao Consumidor Amplo no período de 1980 até 1989.

Tabela 4: Inflação (\%) do Brasil nos anos de 1980 - IPCA

\begin{tabular}{|c|c|}
\hline Data & Inflação \\
\hline 1980 & 99,25 \\
\hline 1981 & 95,62 \\
\hline 1982 & 104,79 \\
\hline 1983 & 164,01 \\
\hline 1984 & 215,26 \\
\hline 1985 & 242,23 \\
\hline 1986 & 79,66 \\
\hline 1987 & 363,41 \\
\hline 1988 & 980,21 \\
\hline 1989 & $1.972,91$ \\
\hline
\end{tabular}

Fonte: IBGE, 2015.

No início dos anos 80 do século 20, o país já apresentava uma inflação de quase 100\% ao ano, em 1989 este valor chega a 1.972,91\% ao ano, apresentando características de uma hiperinflação. Desse modo, o estado brasileiro passava por dificuldades econômicas e a Sudeco dava claros sinais de sua incapacidade administrativa e de planejamento frente ao novo e complexo cenário que se processava com o fim do regime militar, bem como de existência perante a crise financeira e de credibilidade, passando por um processo de esvaziamento durante o governo de José Sarney (1985-1990), que culminou em sua extinção, em 1990, já no governo do presidente Fernando Collor de Mello (1990-1992). Para melhor observar os possíveis avanços socioeconômicos, o próximo tópico abordará aspectos relacionados ao desenvolvimento social da região Centro-Oeste.

\section{Elementos socioeconômicos do Centro-Oeste no período de atuação da Primeira Sudeco (1967-1990)}


Os indicadores socioeconômicos são de fundamental importância para avaliar políticas de desenvolvimento regional e observar se as diversas medidas adotadas se transformaram em benefícios para a sociedade em geral. A figura 10 mostra dois importantes índices de desigualdade: o Theil e o coeficiente de Gini.

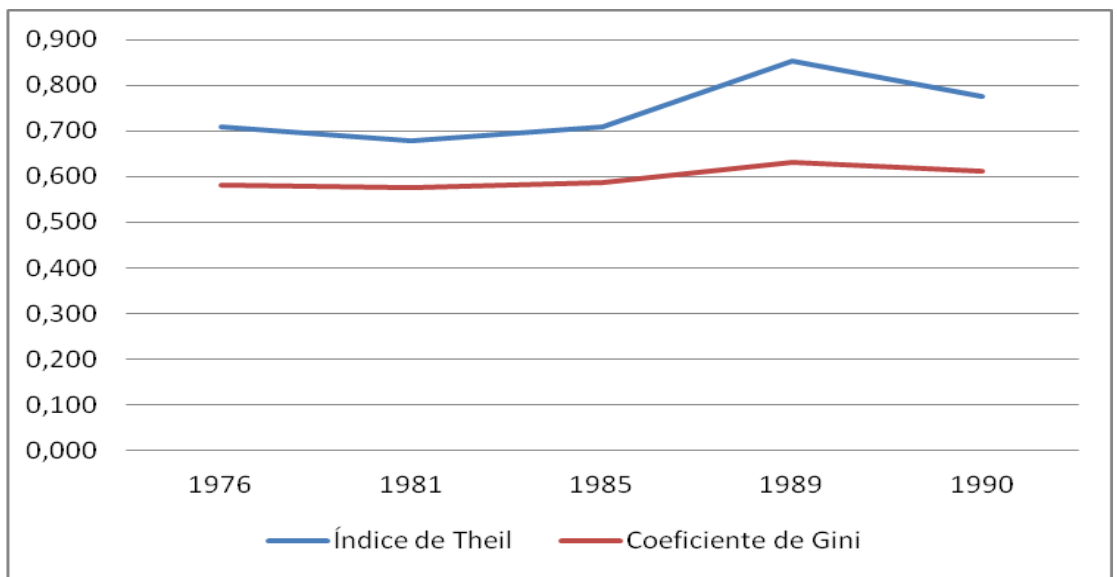

Figura 10: Índice de desigualdade de Theil e coeficiente de Gini do Centro-Oeste. Fonte: IPEA, 2015.

Segundo o IPEA (2015) o índice de desigualdade de Theil mede a desigualdade de acordo com a renda domiciliar per capita, ou seja, mensura a desigualdade na distribuição de indivíduos utilizando a razão entre as médias aritméticas e geométricas da renda familiar per capita média, valendo-se da Pesquisa Nacional por Amostra de Domicílios (Pnad/IBGE). Já o coeficiente de Gini, que também é um indicador de desigualdade de renda, mensura o grau de desigualdade na distribuição da renda domiciliar per capita entre os indivíduos, seu valor pode variar teoricamente entre 0 (quando as rendas dos indivíduos tem o mesmo valor) e 1 (quando as desigualdade nas rendas é mais elevada).

Analisando a figura 10, é possível observar que a desigualdade de renda na região Centro-Oeste apresenta uma trajetória similar entre os dois indicadores, evidencia pouca modificação na comparação entre o início e o fim da série, revelando que a desigualdade de renda não apresentou mudanças significativas no período analisado.

Quando se trata de mortalidade infantil os dados revelam uma grande melhora, como pode ser observado na tabela 5 . 
Tabela 5: Taxa de mortalidade infantil do Centro-Oeste.

\begin{tabular}{|r|r|}
\hline Ano & Taxa \\
\hline 1960 & 115 \\
\hline 1965 & 99 \\
\hline 1970 & 89,7 \\
\hline 1975 & 77 \\
\hline 1980 & 69,6 \\
\hline 1985 & 47,1 \\
\hline 1990 & 31,2 \\
\hline
\end{tabular}

Fonte: IBGE, 2015.

Os dados da tabela 5 revelam que a mortalidade infantil diminui consideravelmente, saindo de 115 mortes no primeiro ano de vida por mil recémnascidos em 1960, para 31,2 em 1990. Já a tabela 6 demonstra o percentual de domicílios com água potável na região.

Tabela 6: Domicílios com água potável no Centro-Oeste (\%).

\begin{tabular}{|clll|}
\hline Estado & $\mathbf{1 9 7 0}$ & $\mathbf{1 9 8 0}$ & $\mathbf{1 9 9 1}$ \\
\hline Distrito Federal & 53,26 & 83,14 & 87,75 \\
Goiás & 34,62 & 53,26 & 78,28 \\
Mato Grosso do Sul & 31,76 & 45,85 & 80,95 \\
Mato Grosso & 49,52 & 69,18 & 88,25 \\
\hline
\end{tabular}

Fonte: IPEA, 2015.

O percentual de domicílios com acesso a água potável melhorou significativamente na região Centro-Oeste no período de 1970 a 1991, isto pode se refletir em uma melhor qualidade de vida para a sociedade. Entretanto, quando se analisa a pobreza as melhoras não são tão efetivas.

A figura 11 revela a proporção de domicílio com renda per capita inferior a linha de extrema pobreza, neste ponto, nota-se uma estabilidade no caso do Distrito Federal e uma piora nos demais estados, evidenciando a elevação da pobreza apesar do crescimento econômico e das políticas de desenvolvimento regional. 


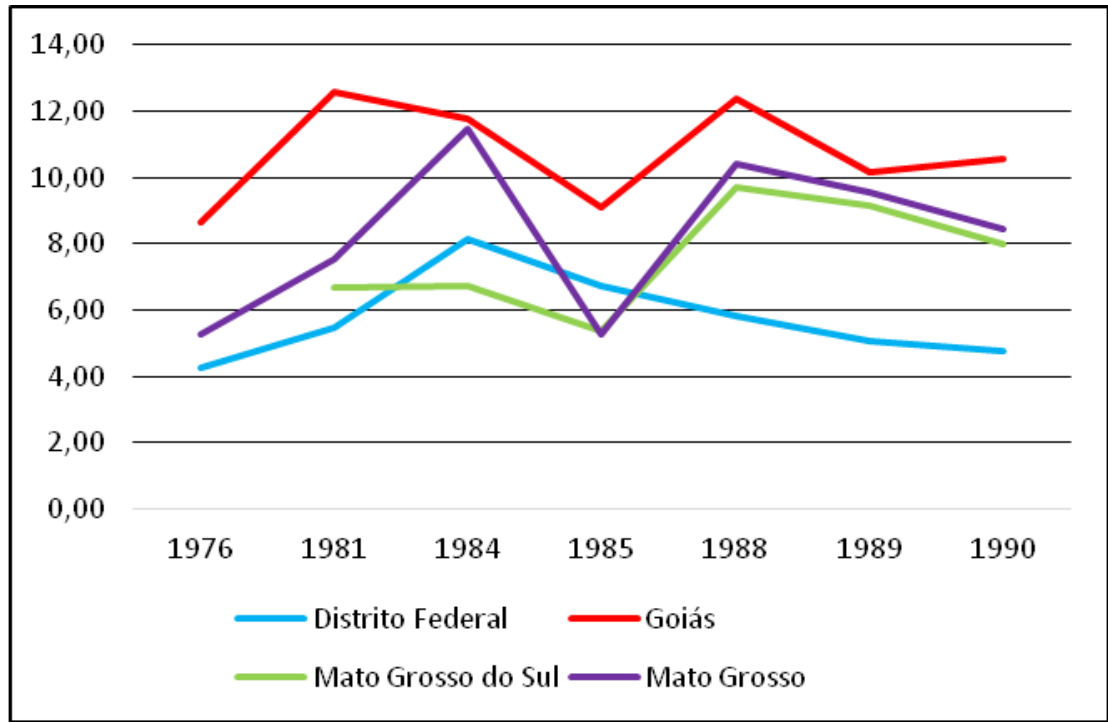

Figura 11: Proporção de domicílios com renda domiciliar per capita inferior à linha de extrema pobreza no Centro-Oeste (\%). Fonte: IPEA, 2015.

No mercado de trabalho houve considerável aumento da população ocupada (aquela que trabalhou nos últimos 12 meses anteriores à pesquisa), de quase três vezes, passando de 1.370,896 pessoas em 1970 para 3.714,414 em 1991. Isto indica dinamismo no mercado de trabalho da região CO. Outro importante campo social a ser verificado é a área educacional.

A figura 12 mostra a evolução da taxa de analfabetismo (percentual de pessoas de 15 ou mais anos de idade que não sabem ler nem escrever um bilhete simples), no CO e revela uma importante redução na taxa de analfabetismo, demonstrando um avanço ao longo do período analisado.

Assim, podemos observar que a região $\mathrm{CO}$ apresentou melhoras de alguns indicadores sociais como: analfabetismo, acesso a água potável, população ocupada e mortalidade infantil. Mas outros aspectos fundamentais para o desenvolvimento regional foram insatisfatórios como desigualdade econômica e domicílios com renda per capita inferior a linha de extrema. Desse modo, o processo de desenvolvimento não refletiu em benefícios sociais plenos. 


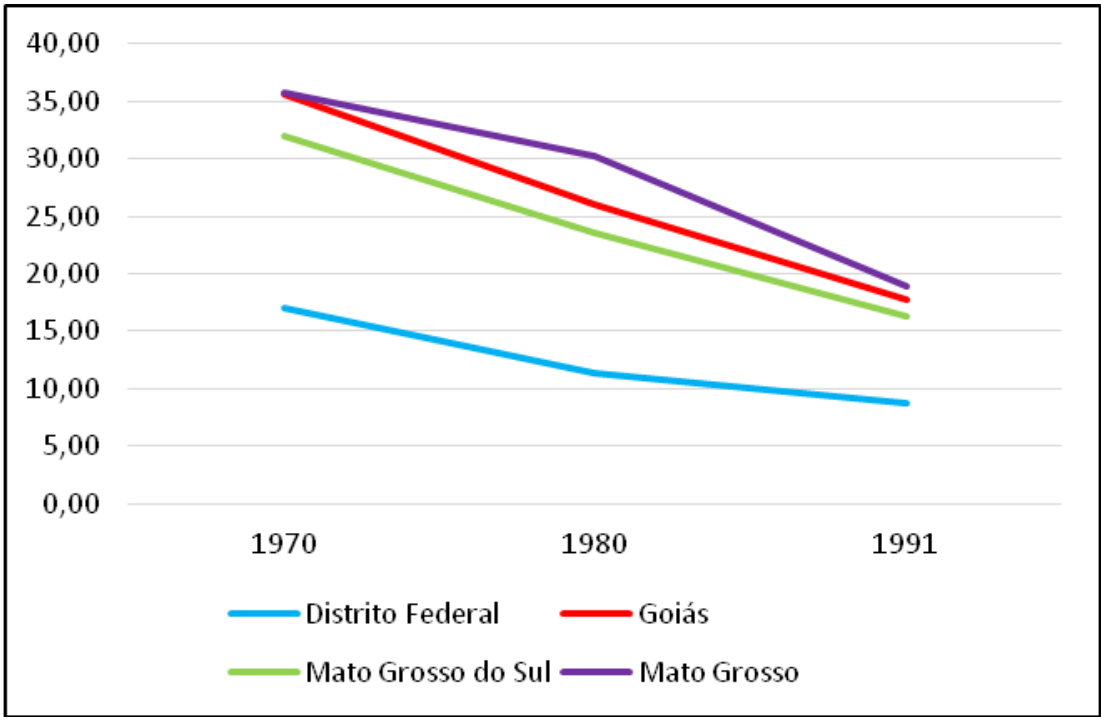

Figura 12: Taxa de analfabetismo no Centro-Oeste (\%). Fonte: IPEA, 2015.

\section{Considerações Finais}

Concebida no contexto do governo militar como órgão de planejamento regional, a primeira Sudeco utilizou-se do discurso desenvolvimentista e do conceito de polo de desenvolvimento para inserir o $\mathrm{CO}$ ao contexto produtivo nacional e internacional. Uma instituição estatal que pouco planejou, mas que se utilizou da estratégia de selecionar áreas-programas para receberem os recursos e investimentos do governo, conduzindo o dito desenvolvimento regional aos interesses do capital industrial.

A Primeira Sudeco priorizou investimentos em setores que dinamizassem a agricultura de exportação, a pecuária, o extrativismo e a atividade mineradora; uma instituição a serviço do capital monopolista, que teve no Estado brasileiro um importante aliado. A criação da Sudeco foi uma importante estratégia para o avanço da fronteira econômica do país, a promoção da grande empresa rural, o zoneamento de atividades econômicas em áreas-programas, o aumento da produção agrícola dentro de padrões pré-estabelecidos, a fixação de imigrantes e a ocupação dos territórios com elevação da população efetiva total, que se deu concentrada em poucas cidades em conformidade com o processo de desenvolvimento por polos.

Sua ação contribuiu para a mecanização e agroindustrialização de atividades agrícolas com predominância de avanço na criação de novas pastagens artificiais, aumento de área plantada e de produção de soja e milho, avanço no estoque de máquinas e equipamentos agropecuários e evolução do setor industrial de forma concentrada, principalmente no estado de Goiás. 
Apesar dos avanços em alguns importantes indicadores socioeconômicos como diminuição da mortalidade infantil e queda na taxa de analfabetismo, não é possível atribuir os avanços sociais às políticas da Sudeco, uma vez que essas melhorias se deram em todas as regiões do país, sem dizer que o campo social não era a prioridade de ação da Superintendência.

\section{Referências Bibliográficas}

ABREU, Silvana de. Planejamento governamental: a SUDECO no espaço MatoGrossense - contexto, propósitos e contradições. 328f. Tese (Doutorado em Geografia Humana) - FFLCH-USP, 2001.

ANDRADE, Manuel Correia de. Cidade e campo no Brasil. São Paulo: Brasiliense, 1974.

BRASIL. Diário Oficial da União. Lei n.5.365, de 01 de dezembro de 1967. Cria a Superintendência do Desenvolvimento da Região Centro-Oeste, e dá outras providências. Brasília. Disponível em: http://www2.camara.gov.br/legin/fed/lei/ 19601969/lei-5365-1-dezembro-1967-359109-normaatualizada-pl.pdf. Acesso em: 03 maio 2012.

CANO, Wilson. Desequilíbrios regionais e concentração industrial no Brasil (19301970). $3^{\mathrm{a}}$ ed. São Paulo: UNESP, 2007.

CAVALCANTI, Marcelo Antunes; BARREIRA, Celene Cunha Monteiro Antunes. Ações da Sudeco no desenvolvimento do Centro-Oeste no estado de Goiás. Boletim Goiano de Geografia, Goiana, v.31, n.2, p. 179-191, 2011.

FUNDAÇÃO JOÃO PINHEIRO. Estudos para a redefinição do Programa de Desenvolvimento dos Cerrados - POLOCENTRO. Belo Horizonte: Fundação JP, 1984.

GOVERNO DO ESTADO DO MATO GROSSO DO SUL. Secretaria de Planejamento e Coordenação Geral. O Centro-Oeste e a retomada do desenvolvimento nacional: proposições de Mato Grosso do Sul para o I PND da Nova República. Campo Grande, 1985.

INSTITUTO BRASILEIRO DE GEOGRAFIA E ESTATÍSTICA. Séries estatísticas. Disponível em: http://seriesestatisticas.ibge.gov.br/series.aspx. Acesso em: 20 abril 2015.

INSTITUTO DE PESQUISA ECONÔMICA APLICADA (IPEA). Ipeadata. Disponível em: http://www.ipeadata.gov.br. Acesso em: 19 abril 2015.

LIMA, Ana C. Cruz; SIMÕES, Rodrigo Ferreira. Teorias do desenvolvimento regional e suas implicações de política econômica no pós-guerra: o caso do Brasil. Disponível em: http://www.cedeplar.ufmg.br/pesquisas/td/TD\%20358.pdf. Acesso em: 13 abril 2015. 
MARTINE, George. Fases e faces da modernização agrícola brasileira. Revista Planejamento e Políticas Públicas, São Paulo, n.3, p. 03-44, 1990.

MINISTÉRIO DO INTERIOR. Superintendência de Desenvolvimento do CentroOeste. Integração Nacional: discursos e conferências. Rio de Janeiro, 25 janeiro 1968.

Integração nacional: a responsabilidade do centro-oeste na integração nacional. Conferência pronunciada pelo Superintendente da Sudeco Sebastião Dantes de Camargo Junior. Brasília, 1970.

II Plano Nacional de Desenvolvimento. Programa de Ação do Governo para a Região Centro-Oeste 1975-1979. Brasília, 1974.

MINISTÉRIO DO PLANEJAMENTO. II Plano Nacional de Desenvolvimento (1975-1979). Brasília: Diário Oficial, 06 dezembro 1974.

PERROUX, François. A Economia do século XX. Porto: Herder, 1967.

REGO, José Márcio; MARQUES, Rosa Maria (Orgs.). Economia brasileira. 2. ed. São Paulo: Saraiva, 2003.

SOUZA, N. J. Desenvolvimento polarizado e desequilíbrios regionais no Brasil. Revista Análise Econômica, Porto Alegre, ano 11, n.19, p. 29-59, mar. 1993.

SOUZA, Nali de Jesus. Teoria dos polos, regiões inteligentes e sistemas regionais de inovação. Revista Análise, Porto Alegre, v.16, n.1, p. 87-112, jan./jul. 2005.

Walter Guedes da Silva

Licenciatura e Bacharelado em Geografia pela Universidade Federal do Mato Grosso do Sul. Doutor em Geografia Humana pela Universidade de São Paulo. Prof. do Curso de Geografia da Universidade Estadual do Mato Grosso do Sul. Campo Grande, Mato Grosso do Sul, Brasil. Rua da Paz, 540 - Centro, 79.020250, Campo Grande - MS.

E-mail: guedes@uems.br

\section{Mateus Boldrine Abrita}

Graduado em Ciências Econômicas pela Universidade Federal de Mato Grosso do Sul. Mestre em Ciências Econômicas pela Universidade Estadual de Maringá e Doutorando em Economia pela Universidade Federal do Rio Grande do Sul. Prof. do Curso de Geografia da Universidade Estadual de Mato Grosso do Sul. Campo Grande, Mato Grosso do Sul, Brasil. Rua da Paz, 540 - Centro, 79.020250, Campo Grande - MS.

E-mail: mateusabrita@hotmail.com

Recebido para publicação em setembro de 2015 Aprovado para publicação em junho de 2016 